Bayero Journal of Pure and Applied Sciences, 10(1): 509 - 515

ISSN 2006 - 6996

\title{
ASSESSMENT OF HEAVY METALS CONCENTRATION IN DRINKING WATER SAMPLES FROM SELECTED AREAS OF KAURU LOCAL GOVERNMENT AREA OF KADUNA STATE, NIGERIA
}

\author{
Dogara Kantoma ${ }^{1}$, James Yusuf ${ }^{2}$ and Manaseh Yakubu Bidam ${ }^{3}$ \\ Department of Applied Science, Kaduna Polytechnic, Kaduna - Nigeria \\ *Correspondence author: kantomadogara@gmail.com; Phone No. +2348031592099
}

ABSTRACT

Water is the vital resources for all kinds of lives. As a result of this a lot of studies had been carried out to ascertain the quality of drinking water, mainly by determination of heavy metals present due to their impact on human health. This study was carried out to evaluate the concentration of heavy metals in some selected drinking water samples from Kauru local government area Kaduna state. An AA500GC London Instrument atomic Absorption Spectrophotometer (AAS) was used to determined the heavy metal concentrations. Prior to analysis, the water samples were pre-concentrated and the residue dissolved in $0.5 \mathrm{M}$ nitric acid. This study aimed at assessing the concentration of some trace metal/element in well water, river water and borehole water consumed in Kauru local government area. Five different water samples were analysed for iron, cobalt, chromium, cadmium, nickel, lead, copper, magnesium, zinc, manganese content and their concentration levels compare with WHO specific maximum level. Iron was found to be between 230.3 and $15.90 \mu \mathrm{gl}^{-1}$, Co between

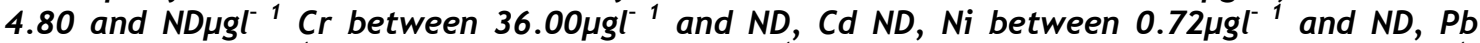
between $6.220 \mu g l^{-1}$ and ND, Cu between $1.72 \mu \mathrm{gl} \mathrm{l}^{-1}$ and ND, Mg between 331.3 and $186.4 \mu \mathrm{gl} \mathrm{I}^{-1}$,

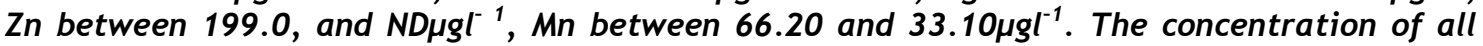
the metals were considerably found to be below the limit permitted by WHO's drinking water guidelines (WHO 2005). Findings suggest that continues water quality monitoring should be carried out to check the concentration levels of heavy metals in that area, to prevent them from been above the limit of WHO.

Keywords: Atomic Absorption Spectrophotometers, Heavy Metals, Water, Kauru Local Government Area.

\section{INTRODUCTION}

Water is one of the most essential elements to life on earth. In its purest form, it's odorless, colorless and tasteless but due to human and animal activities, it is usually contaminated with solid and human waste, effluents from chemical industries and dissolved gases (Jimoh and Umar 2015). Water contaminated by sewage is estimated to kill about two million children every year (Harrison, 1992). The availability of good quality water is an indispensable feature for preventing diseases and improving quality of life (Adefemi and Awokunmi 2007). (Umar, 2015) said many of these minerals are required as micronutrients (small amount). Concentrations of trace elements in water vary because of physiological, environmental and other factors (Sa'id, 2008). Some trace elements have several roles in living organism. Some are essential components of enzymes where they attract substrate molecules and facilitate their conversion to specific end product (Nielson,
2002). In excessive concentrations, however, trace elements can negatively affect growth, reproduction and other biological functions. A safe and portable drinking water should conform to certain standards set by World Health Organisation (WHO) (Okedi, 1997).

The ultimate source of the body trace elements is generally rocks. The concentration of trace element in rocks is varying by rock type, sometimes they become concentrated in soil, water, or in air taken up by plants and ingested by humans or animals (Salem et al., 2000).

Sa'id and Jimoh (2012), carried out study of different water samples taken from some selected areas of Kano metropolis and environs and heavy metals concentrations were measured. Ten water samples (4 wells, 4 boreholes and 2 dams) were analysed using atomic absorption spectrophotometer for their zinc, copper, cadmium and lead content and their levels compare with WHO specified maximum contaminant level. 


\section{MATERIALS AND METHODS}

All reagent used were strictly prepared from chemicals of analytical reagent grade (AnalaR) and deionised water during the analysis; unless stated otherwise. The plastic containers and the glass wares were thoroughly washed with detergent solution, after which it was rinsed thoroughly with tap water, then deionised water and with analytical sample. Water samples were analysed using Atomic Absorption Spectrophotometer (AAS). The AAS was used because it has advantage over colorimetry method due to its high sensitivity detection limit, degree of accuracy and reproducibility with the ease of sample preparation and handling.

\section{Sample Collection}

Five water samples were randomly collected from the various sampling sites (2 wells, 1 boreholes, 2 river/stream, in different areas of Kauru local government area of Kaduna state and were labelled A, B, C,D and E. The water samples were collected in clean five (5) litre polythene plastics containers, the sample containers were rinsed with respective water samples before filling each with the sample. (Said and Jimoh, 2012).

\section{Sample Treatment}

The samples were first allowed to settle followed by filtration. Five (5) litres of each sample were measured and transferred to the new pot for evaporation on sand bath/stove, when the sample are reduced to about a litre it is then transferred to a Pyrex beaker for the completion of the evaporation to dryness (Jimoh and Umar 2015).

Each of the evaporated samples was dissolved in a beaker with $10 \mathrm{ml}$ of $0.5 \mathrm{M}$ nitric acid $\left(\mathrm{HNO}_{3}\right)$. The solution was then filtered in a $30 \mathrm{ml}$ plastic bottle and made up to the mark with $0.5 \mathrm{M} \mathrm{HNO} \mathrm{HN}_{3}$ acid. The addition of nitric acid, stabilizes the samples, maintains oxidation state of the element, make $\mathrm{pH}$ less than 2 and prevent precipitation (ASJ,2012).

\section{Sample Analysis}

Presence and concentration of the 10 metals were analysed in the sample solution (i.e. the filtered solution) using an AA500 GC London instrument atomic absorption spectrophotometer (AAS).

Atomic absorption spectrophotometer is commonly used in many analytical laboratories for determination of trace elements in water samples and in acid digests of sediments or biological tissues (Umar, 2015).

\section{RESULTS AND DISCUSSION}

The use of water for any purpose is guided by standards set by the (WHO) World Health Organization and other related agencies. All the trace metals analysed were considerably below the limit permitted by WHO's drinking water standard (WHO 2011).

Zinc was detected in all samples except B which was not detected, the highest concentration of $199.0 \mu \mathrm{gL}^{-1}$ was detected in sample $C$ and the lowest concentration of $14.85 \mu \mathrm{gL}^{-1}$ was detected in sample A. as shown in Fig. 1.

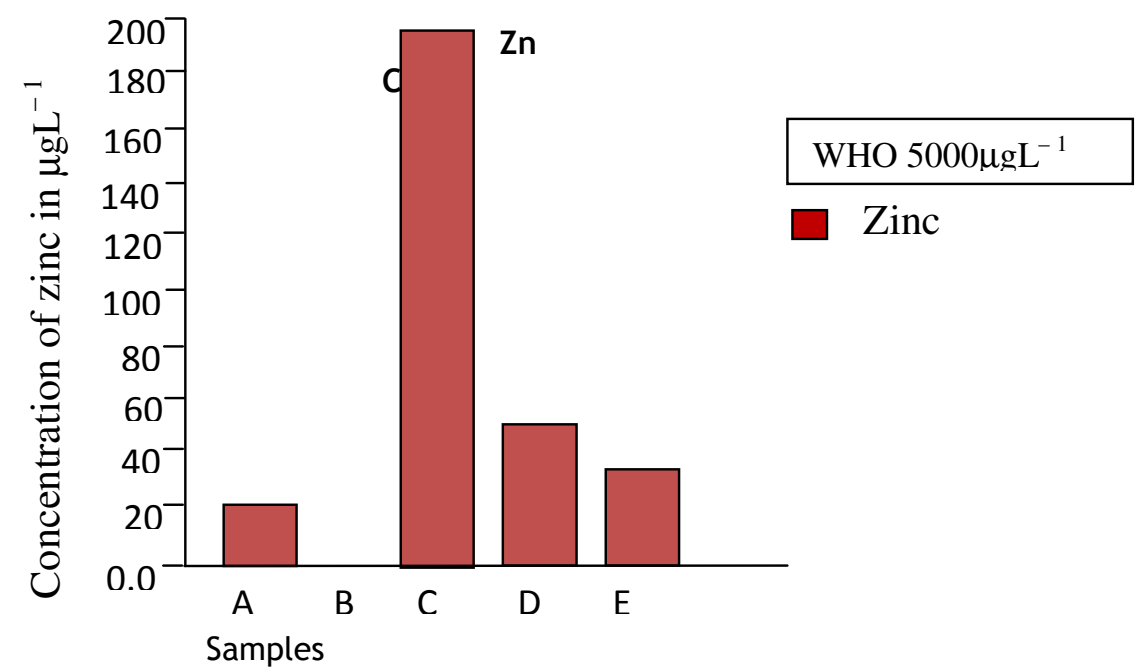

Figure 1: Concentration of zinc in $\mu \mathrm{gL}^{-1}$ in the various water samples. 
The least concentration of zinc was observed in River water while the highest concentration was recorded in well water. All the water samples contain zinc below the WHO maximum permissible limit of $5,000 \mu \mathrm{gL}^{-1}$ (WHO 2011).
Nickel was detected in all the samples. The highest concentration of $4.90 \mu \mathrm{gL}^{-}{ }^{\text {I }}$ was detected in sample $C$ which is well water and not detected was sample $\mathrm{E}$ which is Borehole water as shown in Fig. 2. Most of the results obtained were found to be below the WHO maximum permissible limit of $6 \mu \mathrm{g} / \mathrm{L}$ (WHO 2011).

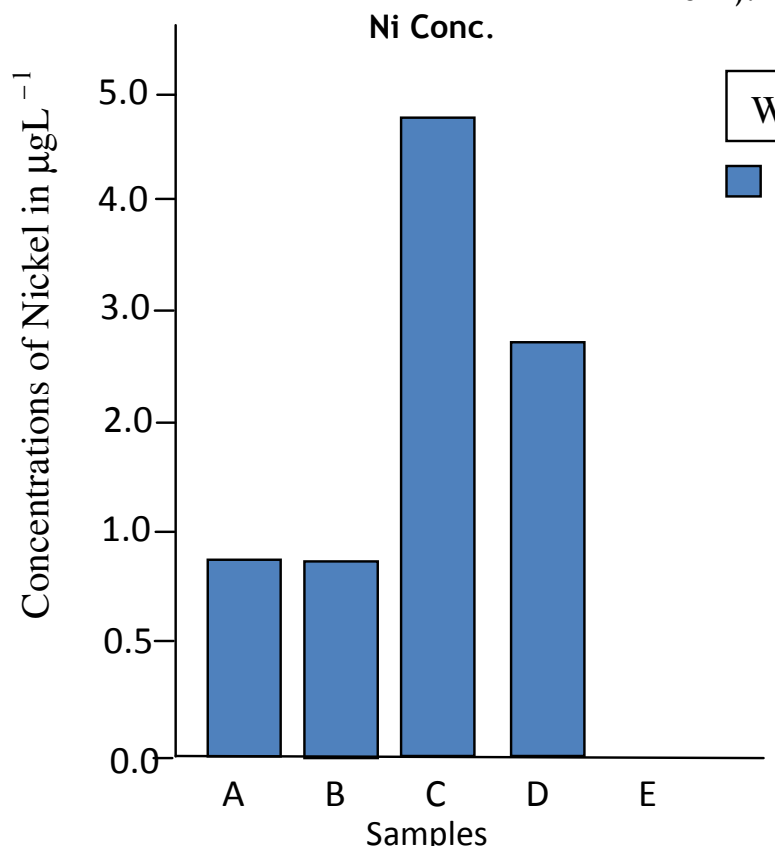

WHO $6 \mu \mathrm{gL}^{-1}$

Nickel

Fig 2: Concentrations of Nickel in $\mu \mathrm{gL}^{-1}$ in the various water samples

Chromium was detected in two samples $C$ and $D$ while in samples $A, B$ and $E$ was not detected. The detected sample has the highest concentrations of $36.00 \mu \mathrm{gL}^{-1}$ as shown in Figure 3.

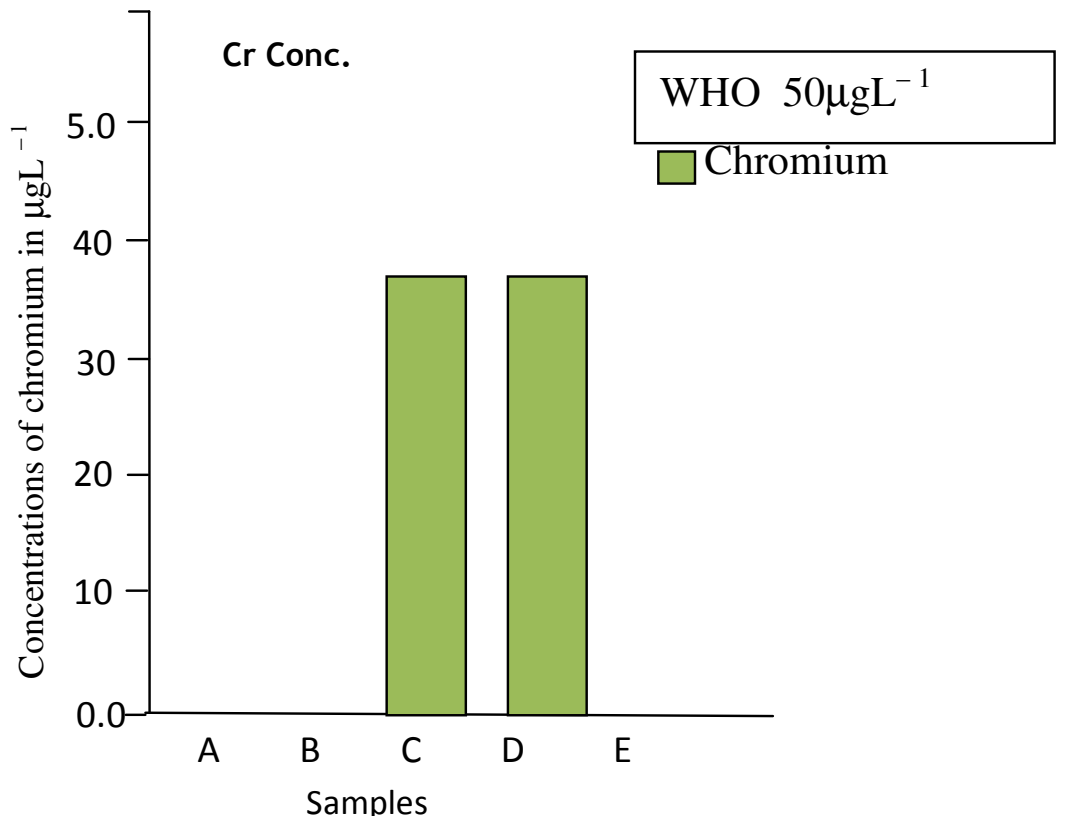

Fig. 3: Concentrations of chromium in $\mu \mathrm{gL}^{-1}$ in the various water samples 
The concentrations of chromium was detected in samples $C$ and $D$ which represent well water. All the samples that chromium was detected are below the WHO maximum permissible limits of $50 \mu \mathrm{gL}^{-1}$ (WHO 2011).
Copper was detected in all the samples excepts samples $A$ and $E$ that was not detected the highest concentration of $1.72 \mu \mathrm{gL}^{-}{ }^{\prime}$ was detected in sample $C$ and the lowest concentration of $0.86 \mu \mathrm{gl}^{-1}$ in samples B and D as shown in Fig. 4.

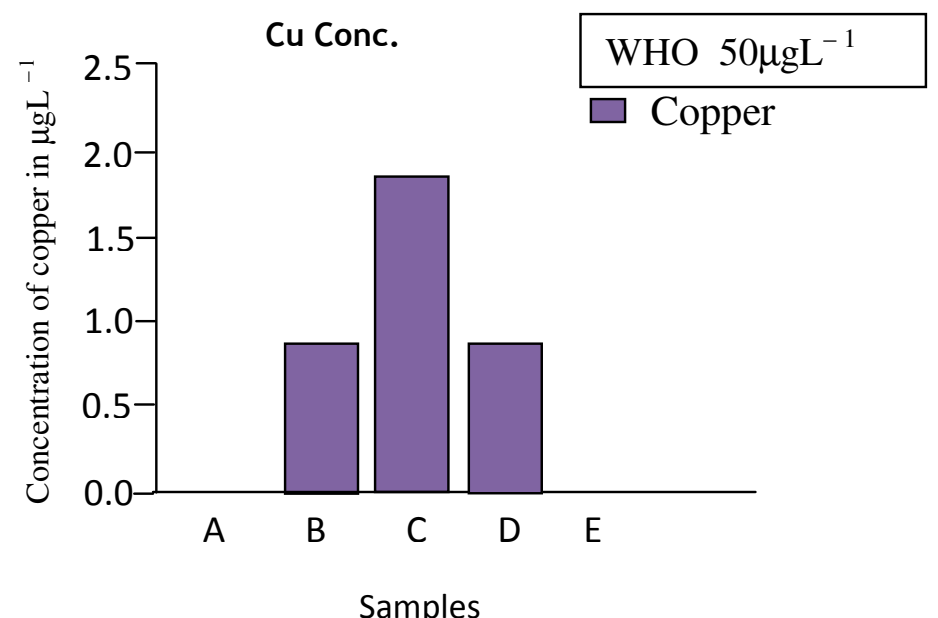

Fig. 4: Concentration of copper in $\mu \mathrm{gL}^{-1}$ in the various water samples.

The highest concentration of copper was in sample C which is well water. All the water samples analysed for copper were found below WHO permissible limits of 50 $\mathrm{gL}^{-1}$ (WHO 2011).
Manganese was detected in all the water samples. The highest concentration of $66.20 \mu \mathrm{gL}$

- I was detected in sample $B$ and $C$ and the lowest concentration of $33.11 \mu \mathrm{gL}$ - I was detected in samples $D$ as shown in figure 5 . Mn Conc.

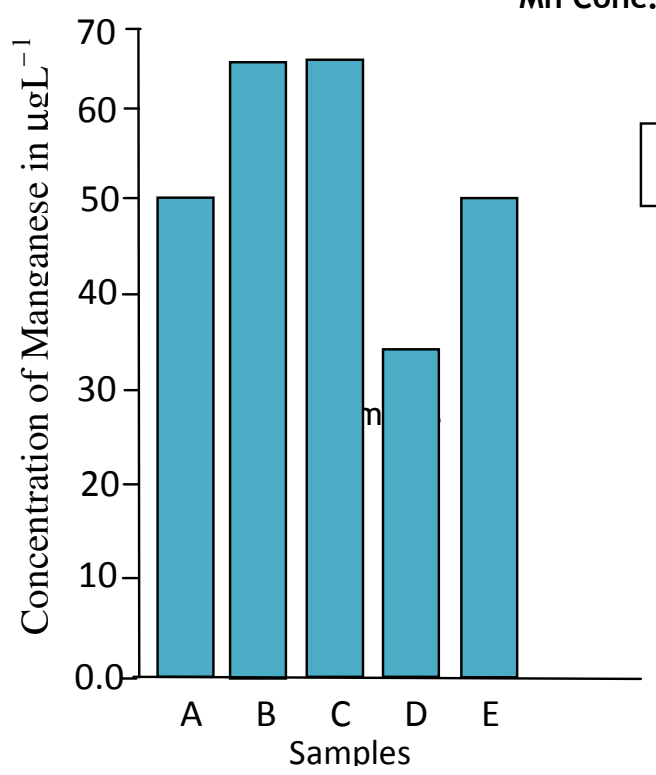

\begin{tabular}{|l|}
\hline WHO $400 \mu \mathrm{gL}^{-1}$ \\
$\square$ Manganese
\end{tabular}

Fig. 5: Concentration of Manganese in $\mu \mathrm{gL}^{-1}$ in the various water samples.

The lowest concentration of manganese was found in well water while the highest concentration was observed in river water. All the water samples analysed were below WHO permissible limits for manganese in drinking of $400 \mu \mathrm{gL}^{-1}$ (WHO 2011). 
Special Conference Edition, November, 2017

The concentration of cobalt in the water samples ranges from not detected to $4.76 \mu \mathrm{gL}^{-1}$ as shown in Fig.7.

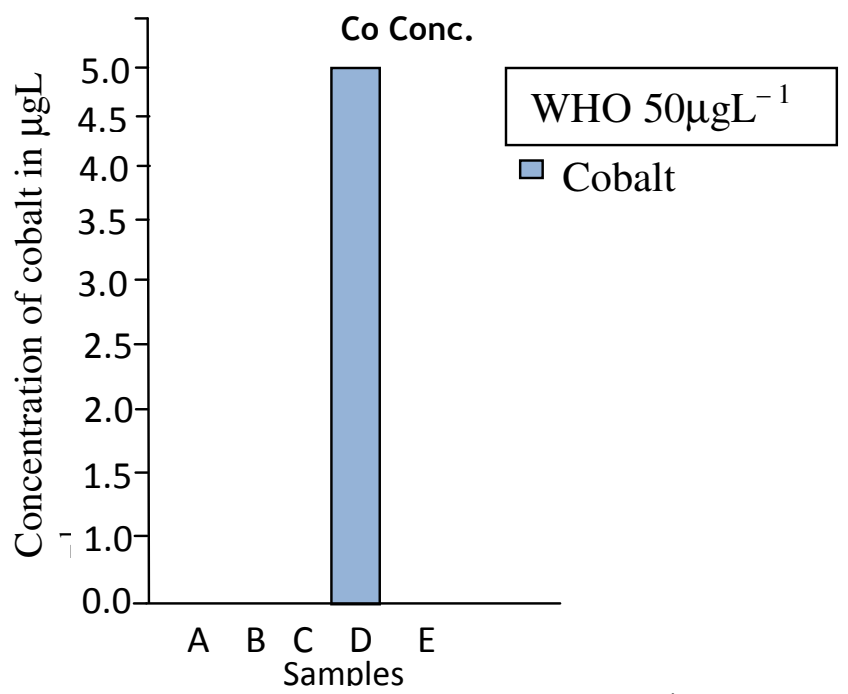

Fig. 6: Concentration of cobalt in $\mu \mathrm{gL}^{-1}$ in the various water samples.

Cobalt was detected only in sample D corresponding to well water. It was not detected in A, B, C and $\mathrm{E}$. The cobalt detected in sample $\mathrm{D}$ was below WHO permissible limits for cobalt in drinking water of $50 \mathrm{\mu gL}^{-1}$ (WHO 2011).

Lead was detected in samples $B$ and $C$ with highest concentration of $6.22 \mu \mathrm{gL}$ - $^{-1}$ and was not detected in samples A, D and $E$ as shown in fig. 7.

$\mathrm{Pb}$ Conc.

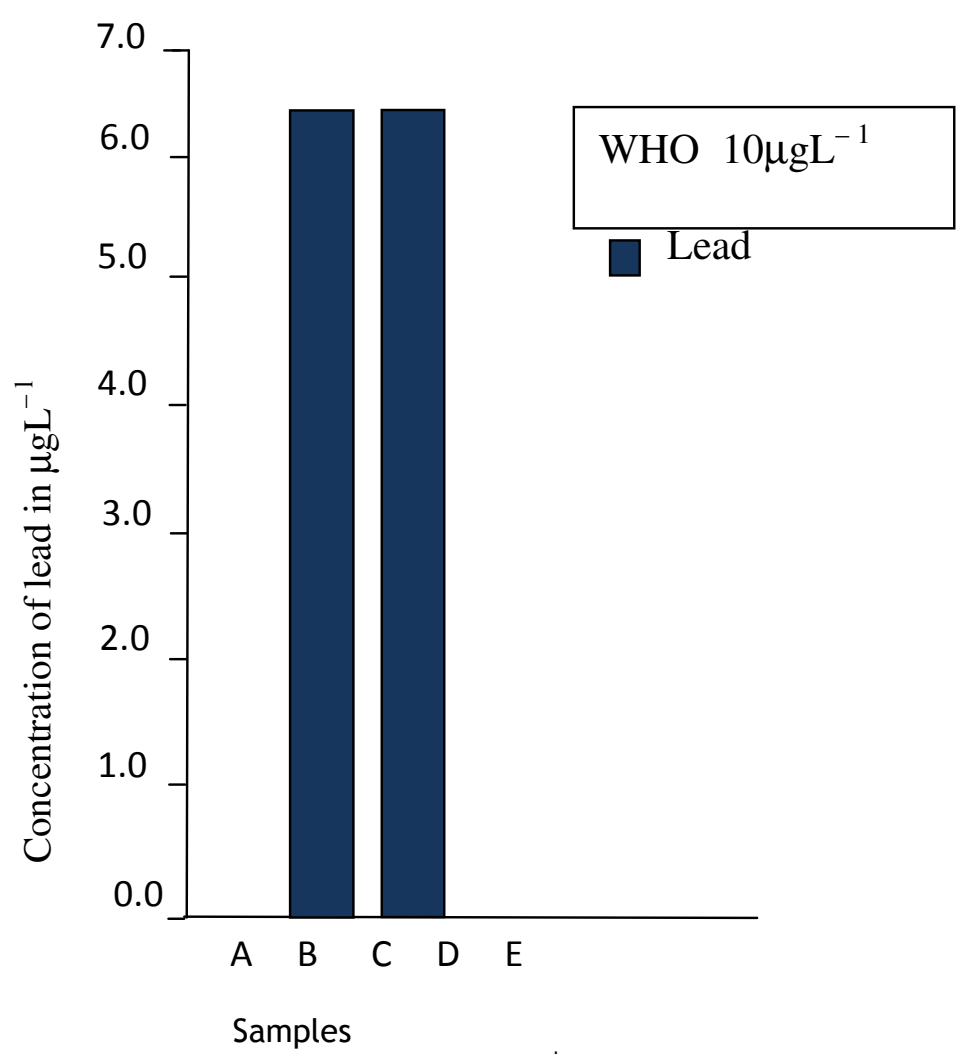

Fig. 7: Concentration of lead in $\mu \mathrm{gL}^{-1}$ in the various water samples 
The concentrations of lead in water samples were found in river water and well water samples while those not detected were borehole water. The lead detected in sample B and C were found below WHO permissible limits for lead in drinking water of $10 \mu \mathrm{gL}^{-1}$ (WHO 2011).

Magnesium was detected in all the water samples with the highest concentration of $331.31 \mu \mathrm{gL}^{-1}$ detected in sample $D$ i.e. well water, and the lowest concentration of $171.76 \mu \mathrm{gL}{ }^{-1}$ detected in sample A i.e. river water was shown in Fig. 8.

Mg Conc.

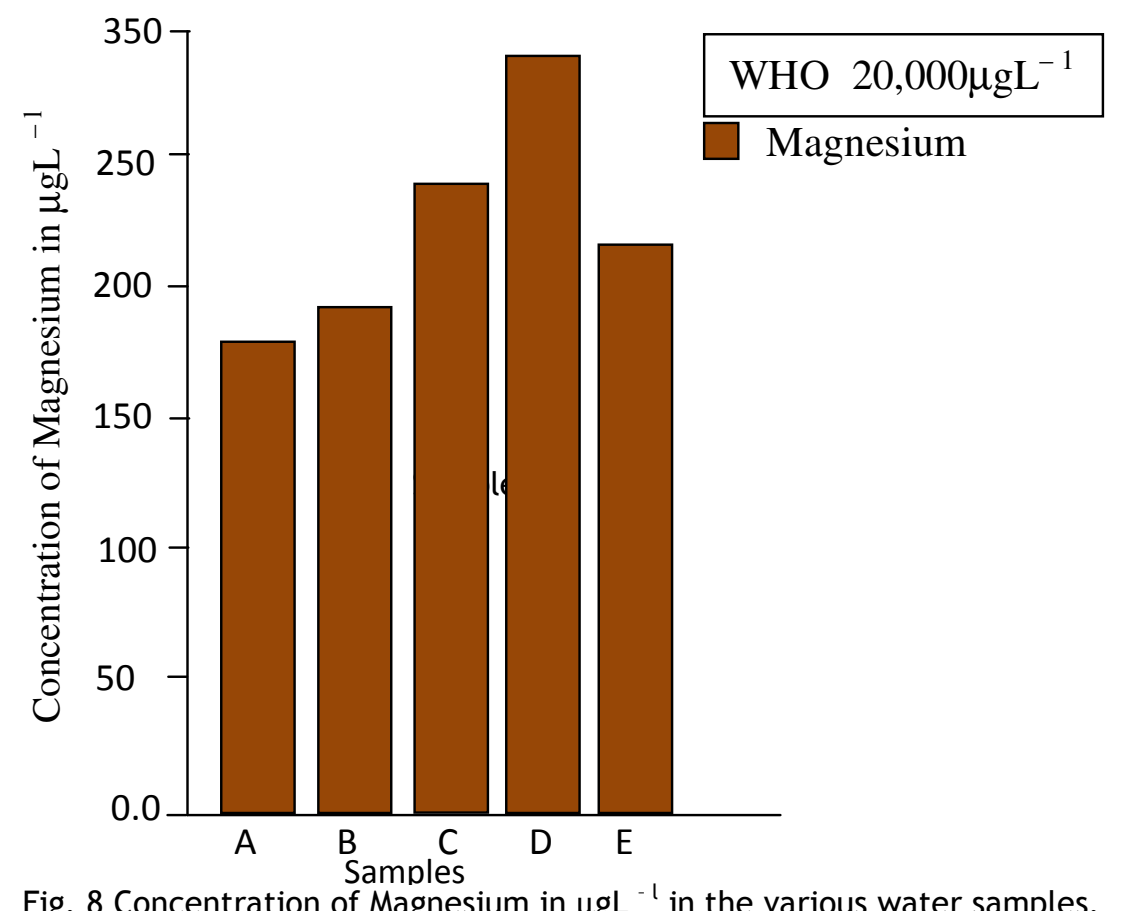

Fig. 8 Concentration of Magnesium in $\mu \mathrm{gL}^{-1}$ in the various water samples.

The lowest concentration of magnesium was detected in river water while the highest concentration was detected in well water. All the water samples analysed were below WHO permissible limits for magnesium in drinking water of 20,000 $\mathrm{gL}^{-1}$ (WHO 2011).

Iron was detected in all the water samples but the highest concentrations of $230.3 \mu \mathrm{gL}^{-}$' was detected in sample $B$ and the lowest concentration of $15.90 \mu \mathrm{gL}^{-1}$ was detected in sample $D$, as shown in Fig. 9 below.

Fe Conc.

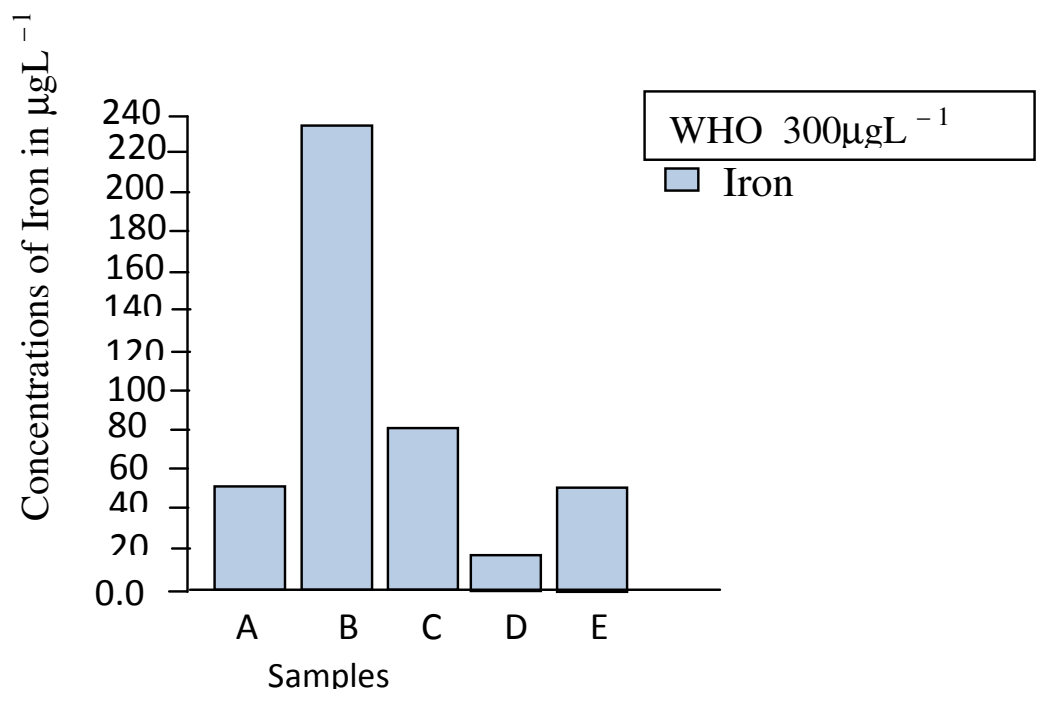

Fig. 9: Concentrations of Iron in $\mu \mathrm{gL}^{-1}$ samples analysed. 
The lowest concentration of iron is detected in borehole while the highest concentration of iron was detected in River water. All samples analysed were below WHO permissible limits for iron in drinking water of $3,000 \mu \mathrm{gL} \mathrm{L}^{-1}$ (WHO 2011).

\section{CONCLUSION}

The result of the analysis of the various water samples showed that the levels of trace elements, $\mathrm{Zn}$, Fe, $\mathrm{Ni}, \mathrm{Cr}, \mathrm{Cu}, \mathrm{Mn}, \mathrm{Co}, \mathrm{Pb}$, and $\mathrm{Mg}$ were below WHO threshold limits while that of cadmium was not detected in any sample at all. This research also showed that iron and magnesium has the highest concentrations.

\section{REFERENCES}

Adefemi, S.O. \& Awokunmi, E. (2007). Assessment of the physic-chemical status of water samples from major dams in Ekiti State, Nigeria. Pak. Nut. 6(6) 657 659.

Analytical Science Journal, ASJ, Vol. no. 1,(2012). Official Journal of Institute of Public Analysts of Nigeria (IPAN).

Harrison, J. (1992). Hydrology and quality of water resources, New York Basic Books. 1992.

Jimoh, W.O. \& Umar, M.I. (2015). Determination of trace metal concentration in drinking water samples from Sani Mainagge Quarter, Gwale local government area, Kano state, Nigeria. International Journal of Science Research in Environmental Sciences. 3(9) pp.03410349, 2015. http: / / www.205pub.com/IJSRes

Nielson, F.H. (2002). Trace mineral deficiencies, in handbook of nutrition and food, edited by Carolyn D. Berdaniex, CRC Press.

\section{Recommendation}

To maintain the balance government should introduce control measures such as providing good site for drinking water, such as boreholes water, tap water to avoid grazing animals from contaminating drinking water as well as industrial effluent should be properly dispensed by treating such drinking water.

This research was conducted only for some trace metals zinc, cadmium, nickel, chromium, copper, manganese, cobalt, lead, magnesium and iron in various drinking water samples. Further research work can be carried out on the concentration of other trace metals, in rainy season, and determine other parameters that was not investigated in this research work.

Okedi, S. (1997). Training guide for water quality testing and control. New York Books, 1997.

Sa'id, M.D. \& Jimoh, W.L.O. (2012) Trace metals concentration in drinking water supplies from some selected areas of Kano metropolis and it's environs, Kano state, Nigeria. Biological and Environmental Science Journal for the Tropics, 9(3):212-214.

Sa'id, M.D. (2008). "Chemical analysis of some water samples across Kano state. Ph.D Thesis, Departme1nt of Pure and Industrial Chemistry Bayero University, Kano. pp.1-4.

Salem, H.M. (2000). "Chemical Analysis of some water samples across Kano State. PhD. Thesis, Department of Pure and Industrial Chemistry Bayero University, Kano Pp. 14.

Umar M. (2015). http://dx.doi/10.1283/ijsres2015 p0301-0349.

WHO (2011). World Health Organization Guidelines for Drinking Water Quality, $4^{\text {th }}$ Edition Geneva, Switzerland. 